\title{
Longitudinal assessment of the association between implementation strategy use and the uptake of hepatitis $C$ treatment: Year 2
}

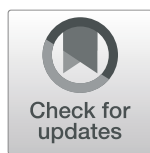

Shari S. Rogal ${ }^{1,2,3^{*}}$ (D), Vera Yakovchenko ${ }^{4}$, Thomas J. Waltz ${ }^{5,6}$, Byron J. Powell ${ }^{7}$, Rachel Gonzalez ${ }^{8}$, Angela Park ${ }^{9}$, Maggie Chartier ${ }^{10}$, David Ross ${ }^{10}$, Timothy R. Morgan ${ }^{8}$, JoAnn E. Kirchner ${ }^{11}$, Enola K. Proctor ${ }^{12}$ and Matthew J. Chinman ${ }^{1,13}$

\begin{abstract}
Background: To increase the uptake of evidence-based treatments for hepatitis C (HCV), the Department of Veterans Affairs (VA) established the Hepatitis Innovation Team (HIT) Collaborative. Teams of providers were tasked with choosing implementation strategies to improve HCV care. The aim of the current evaluation was to assess how site-level implementation strategies were associated with HCV treatment initiation and how the use of implementation strategies and their association with HCV treatment changed over time.

Methods: A key HCV provider at each VA site $(N=130)$ was asked in two consecutive fiscal years $(F Y s)$ to complete an online survey examining the use of 73 implementation strategies organized into nine clusters as described by the Expert Recommendations for Implementing Change (ERIC) study. The number of Veterans initiating treatment for HCV, or "treatment starts," at each site was captured using national data. Providers reported whether the use of each implementation strategy was due to the HIT Collaborative.

Results: Of 130 sites, 80 (62\%) responded in Year 1 (FY15) and 105 (81\%) responded in Year 2 (FY16). Respondents endorsed a median of 27 (IQR19-38) strategies in Year 2. The strategies significantly more likely to be chosen in Year 2 included tailoring strategies to deliver HCV care, promoting adaptability, sharing knowledge between sites, and using mass media. The total number of treatment starts was significantly positively correlated with total number of strategies endorsed in both years. In Years 1 and 2, respectively, 28 and 26 strategies were significantly associated with treatment starts; 12 strategies overlapped both years, 16 were unique to Year 1 , and 14 were unique to Year 2. Strategies significantly associated with treatment starts shifted between Years 1 and 2. Preimplementation strategies in the "training/educating," "interactive assistance," and "building stakeholder interrelationships" clusters were more likely to be significantly associated with treatment starts in Year 1, while strategies in the "evaluative and iterative" and "adapting and tailoring" clusters were more likely to be associated with treatment starts in Year 2. Approximately half of all strategies were attributed to the HIT Collaborative.
\end{abstract}

Conclusions: These results suggest that measuring implementation strategies over time is a useful way to catalog implementation of an evidence-based practice over time and across settings.

Keywords: Learning collaborative, Quality improvement, Cirrhosis, Advanced liver disease, Implementation science

\footnotetext{
* Correspondence: rogalss@upmc.edu

${ }^{1}$ Center for Health Equity Research and Promotion, VA Pittsburgh Healthcare

System, University Drive, Pittsburgh, PA, USA

${ }^{2}$ Department of Surgery, University of Pittsburgh, Pittsburgh, PA, USA

Full list of author information is available at the end of the article
}

(c) The Author(s). 2019 Open Access This article is distributed under the terms of the Creative Commons Attribution 4.0 International License (http://creativecommons.org/licenses/by/4.0/), which permits unrestricted use, distribution, and reproduction in any medium, provided you give appropriate credit to the original author(s) and the source, provide a link to the Creative Commons license, and indicate if changes were made. The Creative Commons Public Domain Dedication waiver (http://creativecommons.org/publicdomain/zero/1.0/) applies to the data made available in this article, unless otherwise stated. 


\section{Background}

Hepatitis $\mathrm{C}$ virus (HCV) is a leading cause of liver cancer and liver failure in the USA [1]. In fiscal year 2015 (FY15), new, highly-efficacious treatments for HCV became widely available as the evidence-based practice for curing $\mathrm{HCV}$ [2]. Prior treatments included injected interferon, which was suboptimal because of side effects, contraindications, and poor efficacy despite year-long treatments. The newer medications included pill-only regimens with minimal side effects, short courses, and high cure rates. As the largest provider for $\mathrm{HCV}$ nationally, the Department of Veterans Affairs (VA) sought to spread this innovation rapidly across the country by developing the Hepatitis $C$ Innovation Team (HIT) Collaborative. Funded by VA leadership as a 4-year, national initiative, the HIT Collaborative supported the development of regional teams of providers with the goal of promoting the uptake of evidence-based $\mathrm{HCV}$ care throughout the VA. The HIT Collaborative included the components of learning or quality improvement collaboratives [3], such as using in-person learning sessions, plan-do-study-act cycles, team calls, email/web-support, external support of active data collection, feedback and education by experts and Collaborative leadership, and outreach to local and national leadership.

Together, the availability of new HCV treatments and VA's implementation efforts to increase their uptake resulted in a dramatic increase in treatment and cure of $\mathrm{HCV}$ in VA. While only $10 \%$ of Veterans with HCV infection had ever been cured of $\mathrm{HCV}$ as of the end of FY14, by the end of FY16, 43\% or 84,192 Veterans were cured, representing a fourfold increase [4].

While this rapid, national implementation effort has been a tremendous success for VA, it has also provided the opportunity to study the use of implementation strategies and their association with a measurable clinical outcome over time and on a national scale. We previously reported on the associations between implementation strategies and HCV treatment starts at the site level and the extent to which strategies were related to HIT activities in the first year of the HIT Collaborative [5]. To frame our evaluation, we used expert-based definitions of implementation strategies, or methods to increase the uptake of evidence-based practices [6,7], from the Expert Recommendations for Implementing Change (ERIC) project. ERIC defined 73 individual strategies [8] and then used a mixed-methods process called concept mapping [9] to develop conceptually distinct clusters of the strategies [10]. As the Collaborative continued, we had the opportunity to study how implementation strategy use changed over time within a nationwide healthcare system, particularly in the context of a learning collaborative [3].

This evaluation aimed to document (1) how reported implementation strategy use evolved over the first two years of the HIT Collaborative, (2) the changes in the associations between implementation strategies and clinical outcomes over time, and (3) the role of the HIT Collaborative in implementation strategy uptake.

\section{Methods}

\section{Assessment of implementation strategies}

Within VA, the HIT Collaborative was led by the National Hepatitis C Resource Center and the Office of Strategic Integration | Veterans Engineering Resource Center with the support of the National HIV, Hepatitis, and Related Conditions (HHRC) Program Office. These data were collected in service of the HIT Collaborative program evaluation, which was reviewed by the VA Pittsburgh Healthcare System IRB and deemed to be a quality improvement project and approved as such by HHRC. All participation in the evaluation was voluntary.

Using implementation strategies as defined by the ERIC project [8] and the clusters of strategies developed by Waltz et al. [10], we created a survey as previously described [5]. The survey asked whether each of the 73 strategies was used to improve HCV care at the site (yes/no) and, if so, whether the use of each strategy could be attributed to support provided by the HIT Collaborative (yes/ no). We emailed providers a link to a web-based survey annually in FY15 (Year 1) and FY16 (Year 2).

\section{Recruitment}

The HIT Collaborative provided the contact information for VA HCV providers and HIT Collaborative members (as listed on the self-provided team rosters) from the 130 VA medical "stations" as classified by Population Health Services of the VA [11]. The individuals who were emailed included providers with varying degrees of affiliation with the HIT Collaborative. Potential participants were emailed twice as a group and once individually by the HIT Collaborative Leadership team following a modified Dillman approach [12]. Additionally, the HIT Collaborative Leadership Team encouraged members to complete the assessment on regularly-scheduled calls.

At sites with more than one respondent, we retained a single response following a "key informant" technique, where a knowledgeable individual answers questions for a site [13]. In the first year, we determined that the responses would be preferentially retained from an $\mathrm{HCV}$ lead clinician. If this person did not respond, then we prioritized responses from the following providers (in descending order of priority): physician, pharmacist, nurse practitioner, physician assistant, other providers, and system redesign staff. In the second year, we prioritized retention from the repeat respondents. If there was not a response from the same person in the second year, then we followed the prioritization scheme as outlined above. Previous experience with the survey and discussions with HIT team members suggested that any of the 
individuals mentioned above would be knowledgeable enough to answer questions about $\mathrm{HCV}$ treatment and the use of implementation strategies.

\section{Data collection}

In addition to collecting site-level implementation strategies in each year, respondents provided information regarding their participation in or affiliation with the HIT Collaborative (members vs. non-members), years in VA, and clinical specialty. Additionally, we classified sites using VA site complexity classifications [14]. These ratings range from levels $1 \mathrm{a}, 1 \mathrm{~b}, 1 \mathrm{c}, 2$, and 3 , in descending order of complexity, and are based on site financial resources, number of patients served, acuity, and services provided. The primary clinical outcome of interest was the number of Veterans started on HCV treatment per year at each site, as defined by VA's Population Health website [11].

\section{Analysis}

We first described the provider and site characteristics in each year. For sites with more than one respondent in a given year, we calculated the interrater reliability. We then assessed the endorsement of strategies to determine which strategies were the most commonly used in Year 2 and the change in strategy use between years. We used chi-square tests to assess the statistical significance of the change in the proportion of participants using each strategy between years. The association between the total number of strategies and the total number of treatment starts was assessed using Pearson's correlation and then linear regression, controlling for site complexity. Next, we assessed which individual strategies were significantly associated with the number of treatment starts using Spearman's test of correlation. Using the map of strategy clusters from Waltz et al. [10], we arrayed the strategies significantly associated with treatment starts in Years 1 and 2 to show how they differed over time. Sensitivity analyses were conducted to assess whether the findings differed between repeat responders and first-time responders in Year 2 (at the site and individual respondent levels). We also assessed differences in responses by HIT membership status using chi-square tests.

For each implementation strategy, we asked participants whether they would attribute their use of the strategy at their site to the HIT Collaborative. We assessed these data by dividing the total number of sites attributing their use of a strategy to the HIT collaborative by the total number of sites endorsing that strategy. We then calculated the proportion of strategies endorsed in each cluster that was attributed to the HIT Collaborative.

\section{Results}

Respondent characteristics

In Year 1 (FY15) and Year 2 (FY16), 62\% and 81\% of 130 VA sites responded to the surveys, respectively. Of these sites, 69 (53\%) responded in both years. The same individual responded in both years in 47 (36\%) of these cases. In Year 2, 23 sites had duplicate responses, and the interrater reliability was 0.65 . There were 11 sites that only responded in Year 1 and 34 sites that only responded in Year 2. The responding sites in Year 2 were responsible for $84 \%$ of all national $\mathrm{HCV}$ treatment starts in that year.

Table 1 shows the respondent characteristics in both years. While there was a trend towards more pharmacy providers and less primary care providers who responded in Year 2 vs. Year 1, this difference was not statistically significant $(p=0.14)$. Otherwise, the general demographic characteristics of the respondents were the same between years. There was a broad distribution of site complexity represented in both years. Notably, not all respondents were affiliated with members of the HIT Collaborative.

The number of patients with $\mathrm{HCV}$ and the numbers and percentages treated in each year are illustrated in Table 2 . Approximately $20 \%$ of patients in the participating sites were treated in Year 1.

\section{Table 1 Respondent characteristics}

\begin{tabular}{|c|c|c|c|c|}
\hline \multirow[b]{2}{*}{ Characteristic } & \multicolumn{2}{|c|}{ Year 1 (FY15) } & \multicolumn{2}{|c|}{ Year 2 (FY16) } \\
\hline & N & $\%$ & $N$ & $\%$ \\
\hline Number of sites (of 130 total) & 80 & 62 & 105 & 81 \\
\hline HIT members & 68 & 85 & 95 & 90 \\
\hline \multicolumn{5}{|l|}{ Years in VA } \\
\hline$<3$ & 13 & 16 & 23 & 22 \\
\hline 4 to 9 & 25 & 31 & 31 & 30 \\
\hline 10 to 19 & 25 & 31 & 38 & 36 \\
\hline$>20$ & 17 & 21 & 13 & 12 \\
\hline \multicolumn{5}{|l|}{ Specialty } \\
\hline Gastroenterology & 33 & 41 & 42 & 40 \\
\hline \multicolumn{5}{|l|}{ Hepatology } \\
\hline Infectious disease & 17 & 21 & 21 & 20 \\
\hline Pharmacy & 13 & 16 & 31 & 30 \\
\hline Primary care & 8 & 10 & 6 & 6 \\
\hline Other (VERC, transplant) & 9 & 11 & 5 & 5 \\
\hline \multicolumn{5}{|l|}{ Site complexity } \\
\hline $1 \mathrm{a}$ & 27 & 33 & 34 & 32 \\
\hline $1 b$ & 14 & 18 & 15 & 14 \\
\hline $1 \mathrm{c}$ & 12 & 15 & 16 & 15 \\
\hline 2 & 14 & 18 & 19 & 18 \\
\hline 3 & 12 & 15 & 21 & 20 \\
\hline
\end{tabular}


Table 2 HCV treatment among VA site and responding sites

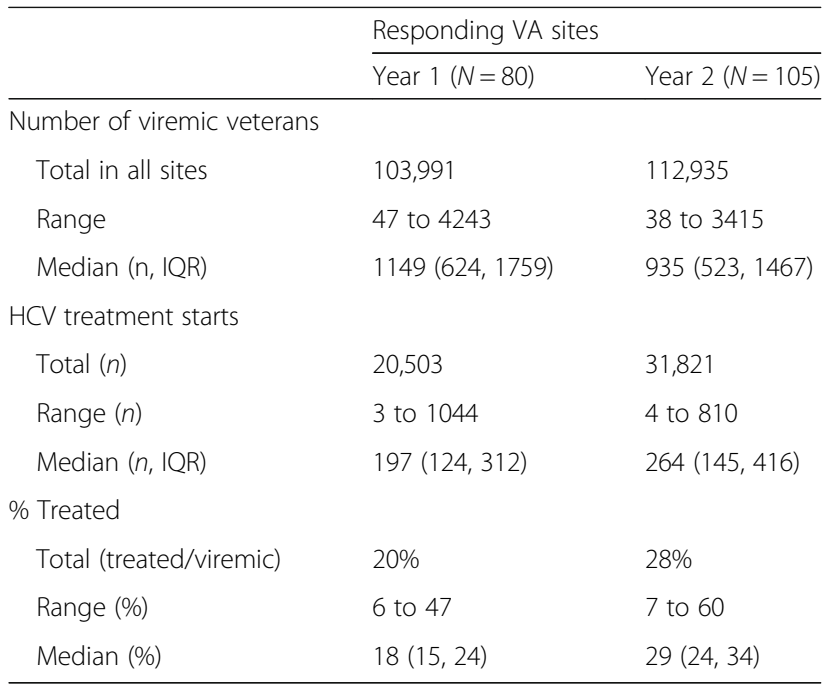

\section{Association between the total number of strategies endorsed and treatment starts}

The FY15 findings were previously published [5] and are presented here for comparison with the FY16 data. A mean of $25 \pm 14$ strategies were endorsed in Year 1 and $28 \pm 14$ strategies in Year 2 . The total number of strategies endorsed was significantly correlated with the number of treatment starts in both years (Year $1 r=$ $0.43, p<0.01$; Year $2 r=0.33, p<0.01)$. The sites in the highest vs. lowest quartile of treatment starts endorsed significantly more strategies in both years (Year 1, 33 vs. 15 strategies; Year 2, 34 vs. 20, $p<0.01$ ). The total number of strategies endorsed was significantly associated with total treatment starts when controlling for site complexity in both years. The adjusted $R^{2}$ for these models was 0.30 in Year 1 and 0.29 in Year 2.

\section{Specific strategies endorsed in each year}

The most commonly used strategies in both years were changing the record system, having the medications on the formulary, using data experts, data warehousing, tailoring strategies, promoting adaptability, engaging patients to be active participants in their care, and intervening with patients to promote uptake/adherence (Table 3). Overall strategy use was largely consistent between the two years; however, there were four strategies with statistically significant differential uptake. Those with increased uptake from FY15 to FY16 were tailoring strategies to deliver $\mathrm{HCV}$ care $(+18 \%)$, promoting adaptability $(+20 \%)$, sharing knowledge $(+19 \%)$, and using mass media $(+18 \%)$. None of the year-to-year decreases met the threshold for significance. At a more categorical level, the evaluative and iterative strategies had the least amount of change between the years, and the strategies in the clusters of engaging consumers and adapting and tailoring to the context had the most positive increases between the two years.

Table 4 shows that the strategies significantly associated with $\mathrm{HCV}$ treatment changed across the two years and that the difference-making strategies varied by year. In Years 1 and 2, respectively, 28 and 26 strategies were significantly associated with treatment starts, 12 strategies overlapped both years, 16 were unique to Year 1, and 14 were unique to Year 2.

Figure 1 illustrates the changes in the strategies significantly associated with treatment starts unique to each year overlaid on the ERIC cluster map, with numbering corresponding to Table 2. The map shows that the significant strategies shifted locations between the years. In Year 1 of availability of the new clinical innovation, the uptake of treatment was significantly associated with strategies in the "provide interactive assistance", "train and educate stakeholders", and "develop stakeholder interrelationships" clusters. In Year 2, the significant strategies were in the "use evaluative and iterative strategies" and adapt and tailor to the context" clusters.

We assessed differences in strategy endorsement between repeat responders and new responders in Year 2. The sites that were newly responding in Year 2 had strategy endorsement patterns more similar to repeat responders' responses in Year 2 than in Year 1. One exception is that in Year 2, newly responding sites were significantly more likely to endorse "change the record" system than repeat sites $(72 \%$ vs. $49 \%, p=0.01$ ). Otherwise, strategy endorsement appeared very similar to that of the Year 2 results for sites that had also responded in Year 1.

Respondents who were participating in the HIT Collaborative were significantly more likely to endorse specific strategies (Table 5). The strategies associated with increased treatment starts are highlighted in bold. Eight of the 10 strategies that were more likely to be endorsed by HIT members in Year 1 were also significantly positively associated with treatment starts in that year. The two strategies that were more likely to be endorsed by HIT members in Year 2 were significantly associated with treatment starts in Year 1 but not Year 2.

\section{Attribution to the HIT Collaborative}

Respondents self-reported whether each strategy they endorsed was used as a result of the HIT Collaborative (or would not have been used if it were not for the HIT Collaborative), and we assessed this in each year and how this changed over time (raw data presented in Additional file 1). Figure 2 shows the total number of sites endorsing each strategy (height of vertical bars) and the proportion that was attributed to the HIT Collaborative (blue). In Year 2, 54\% of all strategy use was attributed to the HIT Collaborative, compared to $41 \%$ in Year 1. The ranges of strategy use and attribution were wide. 
Table 3 Strategy endorsement in each year and change between years

\begin{tabular}{|c|c|c|c|c|}
\hline$\#$ & Strategy and Cluster & $\begin{array}{l}\text { Year } 1 \\
N=80\end{array}$ & $\begin{array}{l}\text { Year } 2 \\
N=105\end{array}$ & Change \\
\hline & Infrastructure & & & \\
\hline 1 & - Change physical structure and equipment & $53 \%$ & $51 \%$ & $-2 \%$ \\
\hline 2 & - Change the record systems & $71 \%$ & $57 \%$ & $-14 \%$ \\
\hline 3 & - Change the location of clinical service sites & $26 \%$ & $37 \%$ & $11 \%$ \\
\hline 4 & $\begin{array}{l}\text { - Develop a separate organization or group responsible for } \\
\text { disseminating HCV care }\end{array}$ & $23 \%$ & $33 \%$ & $10 \%$ \\
\hline 5 & - Mandate changes to HCV care & $55 \%$ & $52 \%$ & $-3 \%$ \\
\hline 6 & - Create or change credentialing and/or licensure standards & $29 \%$ & $30 \%$ & $1 \%$ \\
\hline 7 & $\begin{array}{l}\text { - Participate in liability reform efforts that make clinicians more willing } \\
\text { to deliver the clinical innovation }\end{array}$ & $4 \%$ & $11 \%$ & $7 \%$ \\
\hline \multirow[t]{2}{*}{8} & - Change accreditation or membership requirements & $4 \%$ & $1 \%$ & $-3 \%$ \\
\hline & Financial & & & \\
\hline 9 & - Access new funding & $30 \%$ & $41 \%$ & $11 \%$ \\
\hline 10 & - Alter incentive/allowance structures & $5 \%$ & $10 \%$ & $5 \%$ \\
\hline 11 & $\begin{array}{l}\text { - Provide financial disincentives for failure to implement or use the } \\
\text { clinical innovations }\end{array}$ & $0 \%$ & $2 \%$ & $2 \%$ \\
\hline 12 & - Respond to proposals to deliver HCV care & $44 \%$ & $51 \%$ & $7 \%$ \\
\hline 13 & - Change billing & $11 \%$ & $14 \%$ & $3 \%$ \\
\hline 14 & - Place HCV medications on the formulary & $70 \%$ & $69 \%$ & $-1 \%$ \\
\hline 15 & - Alter patient fees & $0 \%$ & $0 \%$ & $0 \%$ \\
\hline 16 & - Use capitated payments & $0 \%$ & $1 \%$ & $1 \%$ \\
\hline \multirow[t]{2}{*}{17} & - Use other payment schemes & $5 \%$ & $2 \%$ & $-3 \%$ \\
\hline & Support clinicians & & & \\
\hline 18 & - Create new clinical teams & $46 \%$ & $50 \%$ & $4 \%$ \\
\hline 19 & - Facilitate the relay of clinical data to providers & $56 \%$ & $68 \%$ & $12 \%$ \\
\hline 20 & - Revise professional roles & $50 \%$ & $55 \%$ & $5 \%$ \\
\hline 21 & - Develop reminder systems for clinicians & $34 \%$ & $44 \%$ & $10 \%$ \\
\hline \multirow[t]{2}{*}{22} & - Develop resource sharing agreements & $26 \%$ & $35 \%$ & $9 \%$ \\
\hline & Provide interactive assistance & & & \\
\hline 23 & - Use outside assistance often called "facilitation" & $8 \%$ & $12 \%$ & $4 \%$ \\
\hline 24 & $\begin{array}{l}\text { - Have someone from inside the clinic or center (often called "local } \\
\text { technical assistance") tasked with assisting the clinic }\end{array}$ & $15 \%$ & $25 \%$ & $10 \%$ \\
\hline 25 & - Provide clinical supervision & $44 \%$ & $48 \%$ & $4 \%$ \\
\hline \multirow[t]{2}{*}{26} & - Use a centralized system to deliver facilitation & $28 \%$ & $28 \%$ & $0 \%$ \\
\hline & Adapt and tailor to context & & & \\
\hline 27 & - Use data experts to manage HCV data & $58 \%$ & $70 \%$ & $12 \%$ \\
\hline 28 & - Use data warehousing techniques & $85 \%$ & $91 \%$ & $6 \%$ \\
\hline 29 & - Tailor strategies to deliver HCV care & $63 \%$ & $81 \%$ & $18 \% *$ \\
\hline \multirow[t]{2}{*}{30} & - Promote adaptability & $55 \%$ & $75 \%$ & $20 \% *$ \\
\hline & Train and educate stakeholders & & & \\
\hline 31 & - Conduct educational meetings & $51 \%$ & $64 \%$ & $13 \%$ \\
\hline 32 & - Have an expert in HCV care meet with providers to educate them & $41 \%$ & $53 \%$ & $12 \%$ \\
\hline 33 & - Provide ongoing HCV training & $49 \%$ & $60 \%$ & $11 \%$ \\
\hline 34 & - Facilitate the formation of groups of providers and fostered a collaborative learning environment & $44 \%$ & $43 \%$ & $-1 \%$ \\
\hline 35 & - Developed formal educational materials & $39 \%$ & $35 \%$ & $-4 \%$ \\
\hline 36 & - Distribute educational materials & $55 \%$ & $55 \%$ & $0 \%$ \\
\hline 37 & - Provide ongoing consultation with one or more HCV treatment experts & $58 \%$ & $71 \%$ & $13 \%$ \\
\hline 38 & - Train designated clinicians to train others & $20 \%$ & $26 \%$ & $6 \%$ \\
\hline
\end{tabular}


Table 3 Strategy endorsement in each year and change between years (Continued)

\begin{tabular}{|c|c|c|c|c|}
\hline \# & Strategy and Cluster & $\begin{array}{l}\text { Year } 1 \\
N=80\end{array}$ & $\begin{array}{l}\text { Year } 2 \\
N=105\end{array}$ & Change \\
\hline 39 & $\begin{array}{l}\text { - Vary the information delivery methods to cater to different learning } \\
\text { styles when presenting new information }\end{array}$ & $36 \%$ & $36 \%$ & $0 \%$ \\
\hline 40 & - Give providers opportunities to shadow other experts in HCV & $33 \%$ & $22 \%$ & $-11 \%$ \\
\hline \multirow[t]{2}{*}{41} & - Use educational institutions to train clinicians & $11 \%$ & $15 \%$ & $4 \%$ \\
\hline & \multicolumn{4}{|l|}{ Develop stakeholder interrelationships } \\
\hline 42 & - Build a local coalition/team to address challenges & $53 \%$ & $53 \%$ & $0 \%$ \\
\hline 43 & - Conduct local consensus discussions & $48 \%$ & $54 \%$ & $6 \%$ \\
\hline 44 & $\begin{array}{l}\text { - Obtain formal written commitments from key partners that state what } \\
\text { they will do to implement HCV care }\end{array}$ & $4 \%$ & $4 \%$ & $0 \%$ \\
\hline 45 & - Recruit, designate, and/or train leaders & $26 \%$ & $23 \%$ & $-3 \%$ \\
\hline 46 & - Inform local opinion leaders about advances in HCV care & $49 \%$ & $46 \%$ & $-3 \%$ \\
\hline 47 & $\begin{array}{l}\text { - Share the knowledge gained from quality improvement efforts with } \\
\text { other sites outside your medical center }\end{array}$ & $38 \%$ & $57 \%$ & $19 \% *$ \\
\hline 48 & - Identify and prepare champions & $50 \%$ & $52 \%$ & $2 \%$ \\
\hline 49 & $\begin{array}{l}\text { - Organize support teams of clinicians who are caring for patients with } \\
\text { HCV and given them time to share the lessons learned and support } \\
\text { one another's learning }\end{array}$ & $26 \%$ & $32 \%$ & $6 \%$ \\
\hline 50 & $\begin{array}{l}\text { - Use advisory boards and interdisciplinary workgroups to provide input } \\
\text { into HCV policies and elicit recommendations }\end{array}$ & $26 \%$ & $22 \%$ & $-4 \%$ \\
\hline 51 & - Seek the guidance of experts in implementation & $44 \%$ & $50 \%$ & $6 \%$ \\
\hline 52 & $\begin{array}{l}\text { - Build on existing high-quality working relationships and networks to } \\
\text { promote information sharing and problem solving related to } \\
\text { implementing HCV care }\end{array}$ & $61 \%$ & $71 \%$ & $10 \%$ \\
\hline 53 & - Use modeling or simulated change & $13 \%$ & $15 \%$ & $2 \%$ \\
\hline 54 & - Partner with a university to share ideas & $14 \%$ & $11 \%$ & $-3 \%$ \\
\hline 55 & - Make efforts to identify early adopters to learn from their experiences & $16 \%$ & $24 \%$ & $8 \%$ \\
\hline 56 & $\begin{array}{l}\text { - Visit other sites outside your medical center to try to learn from their } \\
\text { experiences }\end{array}$ & $15 \%$ & $20 \%$ & $5 \%$ \\
\hline 57 & - Develop an implementation glossary & $3 \%$ & $6 \%$ & $3 \%$ \\
\hline \multirow[t]{2}{*}{58} & - Involve executive boards & $23 \%$ & $33 \%$ & $10 \%$ \\
\hline & \multicolumn{4}{|l|}{ Use evaluative and iterative strategies } \\
\hline 59 & - Assess for readiness and identify barriers and facilitators to change & $26 \%$ & $30 \%$ & $4 \%$ \\
\hline 60 & - Conduct a local needs assessment & $45 \%$ & $43 \%$ & $-2 \%$ \\
\hline 61 & - Develop a formal implementation blueprint & $34 \%$ & $36 \%$ & $2 \%$ \\
\hline 62 & - Start with small pilot studies and then scale them up & $23 \%$ & $25 \%$ & $2 \%$ \\
\hline 63 & $\begin{array}{l}\text { - Collect and summarize clinical performance data and give it to clinicians } \\
\text { and administrators to implement changes in a cyclical fashion using } \\
\text { small tests of change before making system-wide changes }\end{array}$ & $21 \%$ & $26 \%$ & $5 \%$ \\
\hline 64 & - Conduct small tests of change, measured outcomes, and then refined these tests & $19 \%$ & $21 \%$ & $2 \%$ \\
\hline 65 & - Develop and use tools for quality monitoring & $41 \%$ & $32 \%$ & $-9 \%$ \\
\hline 66 & $\begin{array}{l}\text { - Develop and organize systems that monitor clinical processes and/or outcomes } \\
\text { for the purpose of quality assurance and improvement }\end{array}$ & $30 \%$ & $28 \%$ & $-2 \%$ \\
\hline 67 & - Intentionally examine the efforts to promote HCV care & $61 \%$ & $69 \%$ & $8 \%$ \\
\hline \multirow[t]{2}{*}{68} & - Develop strategies to obtain and use patient and family feedback & $20 \%$ & $20 \%$ & $0 \%$ \\
\hline & \multicolumn{4}{|l|}{ Engage consumers } \\
\hline 69 & - Involve patients/consumers and family members & $50 \%$ & $61 \%$ & $11 \%$ \\
\hline 70 & - Engage in efforts to prepare patients to be active participants in HCV care & $63 \%$ & $57 \%$ & $-6 \%$ \\
\hline 71 & - Intervene with patients/consumers to promote uptake and adherence to HCV treatment & $71 \%$ & $79 \%$ & $8 \%$ \\
\hline 72 & - Use mass media to reach large numbers of people & $18 \%$ & $36 \%$ & $18 \% *$ \\
\hline 73 & - Promote demand for HCV care among patients through any other means & $40 \%$ & $52 \%$ & $12 \%$ \\
\hline
\end{tabular}

The bold and * represent statistically significant changes between years 
Table 4 Strategies significantly associated with treatment in both years vs. only Year 1 or Year 2

\begin{tabular}{ll}
\hline Both years & Year 1 only \\
\hline Change infrastructure & \\
• Change physical structure/equipment & - Change accreditation or membership requirem \\
- Change the location of clinical service sites & - Liability reform \\
Financial strategies & \\
& \\
Support clinicians & - Develop resource sharing agreements \\
- Create new clinical teams & \\
- Revise professional roles & \\
Provide interactive assistance & - Local technical assistance \\
- Provide clinical supervision & - Use a centralized system to deliver facilitation
\end{tabular}

Adapt and tailor to the context

Year 2 only

Adapt and tailor to the context

Train/educate providers

- Facilitate the formation of groups of providers and foster a collaborative learning environment

Develop stakeholder interrelationships

- Build a local coalition/team to address challenges

- Conduct local consensus discussions

- Recruit, designate, and/or train leaders

- Use modeling or simulated change

- Make efforts to identify early adopters to learn from their experiences

Use evaluative and iterative strategies

- Collect and summarize clinical performance data and give it to clinicians and administrators to implement changes in a cyclical fashion using small tests of change before making system-wide changes
- Conduct educational meetings

- Have an expert in HCV care meet with providers to educate them

- Provide ongoing HCV training

- Vary information delivery methods

- Partner with a university

- Visit other sites outside your medical center to try to learn from their experiences

- Identify and prepare champions

- Inform local opinion leaders

- Share the knowledge gained from quality improvement efforts with other sites

- Build on existing high-quality working relationships and networks to promote information sharing and problem solving

\section{- Use data experts to manage HCV data}

- Use educational institutions to train clinicians

- Distribute educational materials

\author{
- Organize support teams of \\ clinicians who are caring for \\ patients with HCV and given them \\ time to share the lessons learned \\ and support one another's learning \\ - Involve executive boards
}

Facilitate the
to providers
- Assess for readiness and identify barriers and facilitators to change
- Develop a formal implementation blueprint
- Develop and organize systems that monitor clinical processes and/or outcomes for the purpose of quality assurance and improvement - Intentionally examine the efforts to promote HCV care
- Conduct small tests of change, measured outcomes, and then refined these tests
- Develop strategies to obtain and use patient and family feedback

Engage consumers

Since the results were similar in both years, Year 2 (FY16) is presented below.

Table 6 shows the change between years of strategies attributed to the HIT Collaborative. The cluster least likely to be attributed to the Collaborative was "engaging consumers." "Training and educating stakeholders" was also unlikely to be attributed to the HIT Collaborative in Year 1 (27\%), but the percent attribution increased to $40 \%$ in Year 2. There was a $21 \%$ increase in the strategies attributable to the HIT in the "evaluative and iterative" cluster between the two years. HIT members were more likely than non-HIT members to attribute 


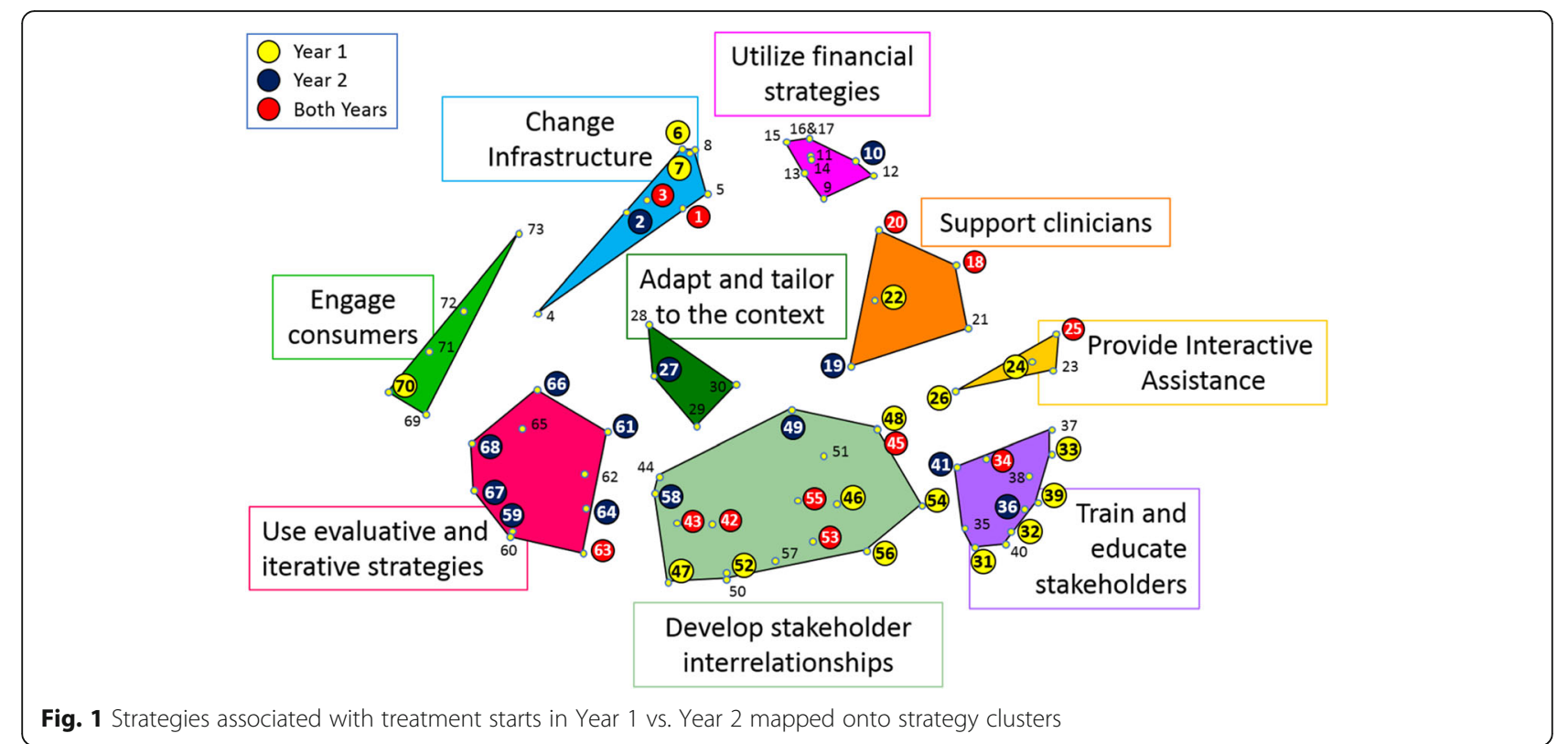

seeking the guidance of experts in implementation (29\% vs. $9 \%, p=0.01)$ and identifying and preparing champions ( $36 \%$ vs. $16 \%, p=0.03)$ to the Collaborative.

\section{Discussion}

We previously examined self-reported use of implementation strategies in a national sample and found that the total number of strategies used by a site was associated with the clinical outcome of HCV treatment starts [5]. In this study, we further investigated the use of strategies over time and the associations between site-level implementation strategy use and treatment starts over time. While many of the strategies did not change in use from Year 1 to Year 2, there was a significant increase in the following specific strategies: tailoring strategies, promoting adaptability, sharing knowledge, and using mass media. Moreover, while the total number of strategies used was associated with increased HCV treatment in each year, the specific strategies associated with treatment starts varied over time.

Table 5 Strategies significantly associated with HIT membership*

\begin{tabular}{|c|c|c|}
\hline Strategy & $\begin{array}{l}\text { Non-HIT member } \\
\text { endorsement (\%) }\end{array}$ & $\begin{array}{l}\text { HIT member } \\
\text { endorsement (\%) }\end{array}$ \\
\hline Year 1 & $N=12$ & $N=68$ \\
\hline - Conduct educational meetings & $17 \%$ & $57 \%$ \\
\hline - Provide ongoing HCV training & $17 \%$ & $54 \%$ \\
\hline - Conduct local consensus discussions & $17 \%$ & $53 \%$ \\
\hline - Use a centralized system to deliver facilitation & $0 \%$ & $32 \%$ \\
\hline $\begin{array}{l}\text { - Share the knowledge gained from quality improvement efforts with other sites } \\
\text { outside your medical center }\end{array}$ & $8 \%$ & $43 \%$ \\
\hline - Tailor strategies to deliver HCV care & $33 \%$ & $68 \%$ \\
\hline - Develop resource sharing agreements & $0 \%$ & $31 \%$ \\
\hline - Build a local coalition/team to address challenges & $25 \%$ & $57 \%$ \\
\hline - Respond to proposals to deliver HCV care & $17 \%$ & $49 \%$ \\
\hline - Provide clinical supervision & $17 \%$ & $49 \%$ \\
\hline Year 2 & $N=10$ & $N=95$ \\
\hline - Inform local opinion leaders about advances in HCV care & $82 \%$ & $100 \%$ \\
\hline - Identify and prepare champions & $84 \%$ & $96 \%$ \\
\hline
\end{tabular}

*Only strategies that were significantly associated with HIT membership are shown in this table; bolded strategies are those associated with treatment starts in that year 


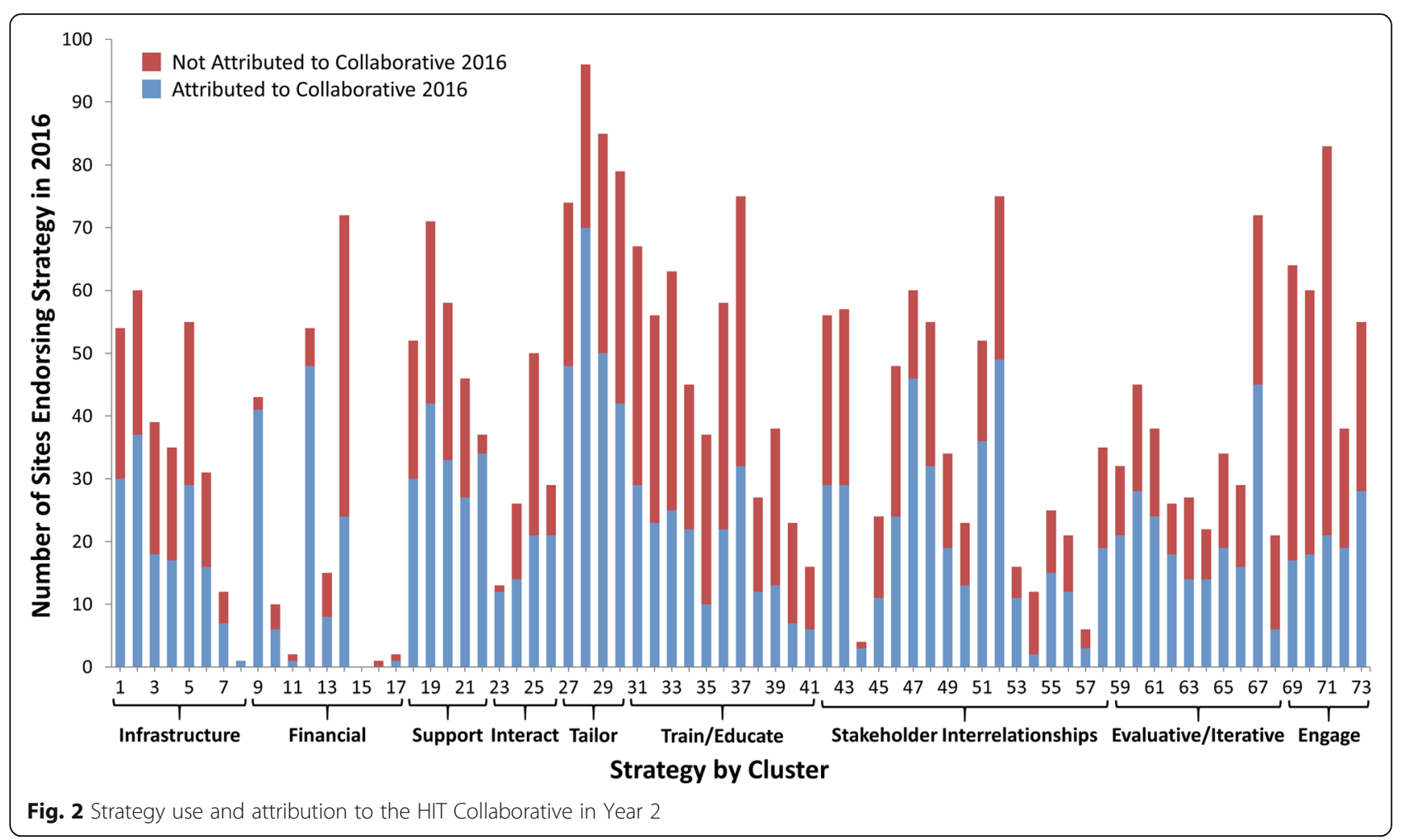

The EPIS Implementation Framework posits that implementation happens along four phases: Exploration, Preparation, Implementation, and Sustainment. The implementation strategies that are appropriate may vary by the stage of implementation [15]. These data support that the implementation strategies associated with successful implementation of a clinical innovation change over time. When the oral $\mathrm{HCV}$ medications/clinical innovation first became available, successful sites focused on preparation or "pre-implementation." The associated implementation strategies included training and education, as well as developing stakeholder interrelationships and seeking interactive assistance. After sites had established the necessary education and relationships, the most successful sites then focused on iterating these and adapting to the context in Year 2. In other words, the strategies associated with treatment shifted across the ERIC group's concept map between years. The geography of this concept map was developed by implementation experts considering the global similarities of the strategies. The present data suggest that clusters and strategies within clusters may be differentially relevant based on the phase(s) of implementation. For example, strategies from the "train and education stakeholders" and "develop stakeholder interrelationships" clusters were important in the first year while the strategies

Table 6 Percentage of strategies attributed to the HIT Collaborative by cluster in each year

\begin{tabular}{llll}
\hline Cluster & \multicolumn{2}{l}{ Percent of strategies attributed to HIT Collaborative } & Change \\
\cline { 2 - 4 } & Year 1 & Year 2 & 6 \\
\hline Change infrastructure & 48 & 54 & 65 \\
Financial strategies & 56 & 63 & 6 \\
Support clinicians & 57 & 58 & 63 \\
Provide interactive assistance & 40 & 63 & 5 \\
Adapt and tailor to the context & 58 & 40 & 13 \\
Train and educate stakeholders & 27 & 59 & 18 \\
Develop stakeholder relationships & 41 & 59 & 21 \\
Use evaluative and iterative strategies & 38 & 34 & 14 \\
Engage consumer & 20 & & 18 \\
\hline
\end{tabular}


within the "use evaluative and iterative strategies" cluster were more closely associated with treatment starts in the second year. A more detailed accounting of the specific phases of implementation that were present over the reporting period could further clarify the relationships between phases of implementation and the strategies used. Our finding that the strategies associated with HCV treatment changed from Year 1 to Year 2 supports the notion that successful sites used evolving strategies as the clinical innovation became more available and as the learning collaborative evolved.

These results must be interpreted in the context of the national HIT Collaborative. The timing of the national efforts to improve HCV care also corresponded to a major shift in the treatment of HCV from difficult-to-use, interferon-based treatments to simple, highly efficacious, curative, pill-based treatments. We aimed to assess how the Collaborative influenced the choice of activities to promote $\mathrm{HCV}$ care and how much of the strategy uptake related to the HIT Collaborative itself versus independent, local activities in response to the availability of these newer HCV medications. We asked providers to comment on whether strategies would have been done without the Collaborative and assessed how members of the Collaborative employed strategies differently than non-members. We found that approximately half of all implementation efforts nationally were attributed to the HIT Collaborative, meaning that providers felt that half of the activities would not have been done without the HIT Collaborative. Moreover, the activities that members of the Collaborative were more likely to engage in were those that are considered to be core elements of learning/quality improvement collaboratives in the literature [3]. For example, education/training, team-building, and communication with leadership are all essential elements of learning collaboratives and were endorsed more frequently by HIT members than non-members. Thus, these analyses are useful in assessing the role of the learning collaborative in the uptake of the clinical innovation via implementation strategy uptake.

While learning collaboratives are increasingly popular, their effectiveness is relatively untested [3]. These data provide preliminary support for the effectiveness of learning collaboratives. For example, strategies that were difference-making in this sample were often those strategies considered to be core components of learning collaboratives including using data relay, training and education, creating new teams, facilitation/technical assistance, and stakeholder interrelationship strategies. Moreover, the ERIC strategy "facilitate the formation of groups of providers and foster a collaborative learning environment" which specifically refers to learning collaboratives was significantly associated with treatment in both years, suggesting that the learning collaborative itself was associated with increased treatment. The HIT
Collaborative specifically focused on building stakeholder interrelationships and using principles of system redesign including rapid cyclic tests of change. Sites frequently endorsed these types of strategies and attributed their uptake to the Collaborative. Additionally, the HIT Collaborative attribution in the "evaluative and iterative" cluster, which was critical to the success in Year 2, increased substantially from Year 1 to 2, indicating that the Collaborative was instrumental to site-level success. Most of the strategies endorsed more often by HIT members vs. non-members were significantly associated with treatment starts. These data thus provide some preliminary support for learning collaboratives as an effective means of increasing the uptake of a clinical innovation or evidence-based practice.

Implementation strategies have historically been difficult to measure. Generally, tracking strategies has been completed by observation and not by self-reporting on a comprehensive list of strategies [16, 17]. While we previously reported on developing a survey using the definitions of implementation strategies from the ERIC study, it remained unclear whether these strategies would be understandably and reliably interpreted by non-implementation scientists. In both years of data collection, we found an association between clinical outcomes with specific implementation strategies. The second year of data collection further demonstrates that providers could interpret and answer questions about implementation strategies. First, there was adequate interrater reliability within sites in both years. Second, there was consistency across the years in that several of the strategies were associated with treatment starts. Third, the strategies that were individually associated with treatment starts were in some cases those strategies supported by implementation literature. For example, facilitation is a well-studied strategy and was associated with higher treatment rates in Year 1 [18-22]. Fourth, we found that the providers were able to generally distinguish between similar strategies. The strategy clusters were designed to group similar strategies, and we did not find strong correlations between endorsement of specific strategies within a cluster. In fact, there was significant variation in endorsement of the strategies within clusters (where the most similar strategies are housed). These findings indicate that such surveys can be used to track implementation strategies across a wide range of provider types, education, and geographic locations.

This study has several notable limitations. First, we relied on year-end self-report of implementation and included only one response per site. We found that the results had face-validity, as outlined above, and there was adequate interrater reliability when we assessed the reports of sites with more than one respondent. However, future studies would benefit from directly observing site-level implementation or documenting the application 
of implementation strategies over the course of the reporting time period. Second, it is unclear if the self-reported attribution data related to increased awareness of the HIT Collaborative or social desirability, given that more of the respondents in Year 2 were HIT members. Theoretically, any strategy could have been "correctly" attributed to the Collaborative, since the Collaborative leadership team encouraged and supported any strategy that the sites felt would be effective. A third limitation is that we included limited contextual factors in our associations between implementation strategy use and clinical outcomes. However, participant characteristics were not significantly associated with strategy endorsement. Given the uniformity of structure within VA, this may be less important, but in applying these lessons to non-VHA sites, more contextual information may have to be collected. We were also unable to assess the timing, sequencing, or intensity of implementation strategies within each year. It may be that specific strategies need to be sequenced in a specific order within the year. While the simple listing of strategies allowed us to quickly collect data from across the country, these data do not detail how the strategies were operationalized by sites. Often the application of implementation strategies may vary broadly and lead to difficulties assessing which elements of a strategy are critical or difference-making [23]. We successfully tracked strategies across the years, which is a strength of these analyses. A final limitation was our limited choice of outcome measures. We considered focusing on the proportion of patients treated as our primary outcome but were concerned that sites with fewer patients would have an artificial advantage, since sites treating half of the patients would look the same, whether they had 20 or 2000 patients to treat. Our findings should be validated in other clinical contexts with other medical problems. Future work in this area could aim to address whether specific combinations of strategies are important or how to use these data to address low-performing sites. Future work could also assess the associations between the sites' stage of implementation [24] and strategy utilization.

\section{Conclusions}

These findings collectively indicate that the strategies associated with the uptake of a clinical innovation change over time from "pre-implementation" strategies including training and education, interactive assistance, and developing stakeholder interrelationships to strategies that are evaluative and iterative and adapt to the context, which indicate a more mature phase of implementation. This research advances the field by providing support for the implementation strategies and clusters developed by the ERIC group. This project demonstrates the utility of deploying surveys of implementation strategies sequentially across the life of a national clinical program, which could provide guidance to other national initiatives.

\section{Additional file}

Additional file 1: Participant attribution of strategies to the HIT Collaborative in each year. (DOCX $18 \mathrm{~kb}$ )

\section{Abbreviations}

ERIC: Expert Recommendations for Implementing Change; FY: Fiscal year; HCV: Hepatitis C virus; HIT: Hepatitis C Innovation Team; IQR: Interquartile range; VA: Department of Veterans Affairs

\section{Acknowledgements}

The contents of this paper are solely from the authors and do not represent the views of the U.S. Department of Veterans Affairs or the U.S. Government.

\section{Funding}

Funding was provided by the HIV, Hepatitis, and Related Conditions Programs to conduct the program evaluation of the VISN Hepatitis Innovation Team Initiative. Funding for Dr. Rogal's time was provided in part by AHRQ grant K12 HS019461 (PI: Kapoor) and the support of the VA Pittsburgh Healthcare System. The preparation of this article was supported in part by the Implementation Research Institute (IRI), at the George Warren Brown School of Social Work, Washington University in St. Louis; through awards from the National Institute of Mental Health (5R25MH08091607) and the Department of Veterans Affairs, Health Services Research \& Development Service, Quality Enhancement Research Initiative (QUERI). BJP was supported by the National Institue of Mental Health (K01MH113806).

Availability of data and materials

All data generated or analyzed during this study are included in this published article.

\section{Authors' contributions}

SR, VY, RG, AP, DR, TM, MC, and MJC helped to conceptualize the study design and data collection tool. The analytical plan was developed by SR, VY, TW, BP, JK, RG, AP, TM, and MJC. SR and VY conducted the analyses. All authors performed significant editing of the manuscript and read and approved the final manuscript.

\section{Ethics approval and consent to participate}

The Pittsburgh VA IRB determined that the initiative was exempt under a provision applying to quality improvement. This study was approved by the HIV, Hepatitis and Related Conditions Programs in the Office of Specialty Care Services as a quality improvement project as a part of the program evaluation for the Hepatitis C Innovation Team Collaborative.

\section{Consent for publication}

Figure 1 is adapted from a previously-published image from Dr. Waltz et al's paper and is used with his permission.

\section{Competing interests}

The authors declare that they have no competing interests.

\section{Publisher's Note}

Springer Nature remains neutral with regard to jurisdictional claims in published maps and institutional affiliations.

\footnotetext{
Author details

${ }^{1}$ Center for Health Equity Research and Promotion, VA Pittsburgh Healthcare System, University Drive, Pittsburgh, PA, USA. ²Department of Surgery, University of Pittsburgh, Pittsburgh, PA, USA. ${ }^{3}$ Division of Gastroenterology, Hepatology, and Nutrition, University of Pittsburgh, Pittsburgh, PA, USA. ${ }^{4}$ Center for Healthcare Organization and Implementation Research, Edith Norse Rogers Memorial VA Hospital, Bedford, MA, USA. ${ }^{5}$ Department of Psychology, Eastern Michigan University, Ypsilanti, MI, USA. ${ }^{6}$ VA Center for Clinical Management Research, VA Ann Arbor Healthcare System, Ann Arbor, MI, USA. Department of Health Policy and Management, Gillings School of Global Public Health, University of North Carolina at Chapel Hill, Chapel Hill, NC, USA. ${ }^{8}$ Gastroenterology Section, VA Long Beach Healthcare System, Long Beach, CA, USA. ${ }^{9}$ Office of Strategic Integration | Veterans Engineering
} 
Resource Center, Washington, DC, USA. ${ }^{10} \mathrm{HIV}$, Hepatitis and Related Conditions Programs, Office of Specialty Care Services, Veterans Health Administration, Washington, DC, USA. "'Department of Veterans Affairs Medical Center, HSR\&D and Behavioral Health Quality Enhancement Research Initiative (QUERI), Central Arkansas Veterans Healthcare System, Little Rock, AR, USA. ${ }^{12}$ Brown School, Washington University in St. Louis, St. Louis, MO, USA. ${ }^{13}$ RAND Corporation, Pittsburgh, PA, USA.

Received: 17 August 2018 Accepted: 25 March 2019

Published online: 08 April 2019

\section{References}

1. Naghavi MWH, Lozano R, et al. Global, regional, and national age-sex specific all-cause and cause-specific mortality for 240 causes of death, 1990 -2013: a systematic analysis for the Global Burden of Disease Study 2013. Lancet. 2015;385(9963):117-71.

2. Wedemeyer $\mathrm{H}$. Towards interferon-free treatment for all HCV genotypes. Lancet. 2015;385(9986):2443-5

3. Nadeem E, Olin SS, Hill LC, Hoagwood KE, Horwitz SM. Understanding the components of quality improvement collaboratives: a systematic literature review. Milbank Q. 2013;91(2):354-94.

4. Belperio PS, Chartier M, Ross DB, Alaigh P, Shulkin D. Curing hepatitis C virus infection: best practices from the U.S. Department of Veterans Affairs. Ann Intern Med. 2017;167(7):499-504.

5. Rogal SS, Yakovchenko V, Waltz TJ, Powell BJ, Kirchner JE, Proctor EK, et al. The association between implementation strategy use and the uptake of hepatitis C treatment in a national sample. Implement Sci. 2017;12(1):60.

6. Proctor EK, Powell BJ, McMillen JC. Implementation strategies: recommendations for specifying and reporting. Implement Sci. 2013;8:139.

7. Waltz TJ, Powell BJ, Chinman MJ, Smith JL, Matthieu MM, Proctor EK, et al. Expert Recommendations for Implementing Change (ERIC): protocol for a mixed methods study. Implement Sci. 2014;9:39.

8. Powell BJ, Waltz TJ, Chinman MJ, Damschroder L, Smith JL, Matthieu MM, et al. A refined compilation of implementation strategies: results from the Expert Recommendations for Implementing Change (ERIC) project. Implement Sci. 2015;10:21.

9. Kane M, Trochim WMK. Concept mapping for planning and evaluation. Thousand Oaks: Sage; 2007.

10. Waltz TJ, Powell BJ, Matthieu MM, Damschroder $\sqcup$, Chinman MJ, Smith J et al. Use of concept mapping to characterize relationships among implementation strategies and assess their feasibility and importance: results from the Expert Recommendations for Implementing Change (ERIC) study. Implement Sci. 2015;10:109.

11. US Department of Veterans Affairs: Veterans Health Administration Office of Public Health. Population health services website: US Department of Veterans Affairs: Veterans Health Administration Office of Public Health; 2017 [Available from: https://vaww.vha.vaco.portal.va.gov/sites/PublicHealth/ pophealth/default.aspx.

12. Thorpe C, Ryan B, McLean SL, Burt A, Stewart M, Brown JB, et al. How to obtain excellent response rates when surveying physicians. Fam Pract. 2009;26(1):65-8.

13. Tremblay M. The key informant technique: a nonethnographic application. Am Anthropol. 1957;59:688-701.

14. VHA Facility Complexity Model Veterans Health Administration; 2015 [Available from: http://opes.vssc.med.va.gov/FacilityComplexityLevels/ Pages/default.aspx. Accessed 22 Nov 2017.

15. Aarons GA, Hurlburt M, Horwitz SM. Advancing a conceptual model of evidence-based practice implementation in public service sectors. Admin Pol Ment Health. 2011;38(1):4-23.

16. Bunger AC, Powell BJ, Robertson HA, MacDowell H, Birken SA, Shea C. Tracking implementation strategies: a description of a practical approach and early findings. Health Res Policy Syst. 2017;15(1):15.

17. Boyd MR, Powell BJ, Endicott D, Lewis CC. A method for tracking implementation strategies: an exemplar implementing measurement-based care in community behavioral health clinics. Behav Ther. 2018;49(4):525-37.

18. Kirchner JE, Ritchie MJ, Pitcock JA, Parker LE, Curran GM, Fortney JC. Outcomes of a partnered facilitation strategy to implement primary care-mental health. J Gen Intern Med. 2014;29(Suppl 4):904-12.

19. Ritchie MJ, Parker LE, Edlund CN, Kirchner JE. Using implementation facilitation to foster clinical practice quality and adherence to evidence in challenged settings: a qualitative study. BMC Health Serv Res. 2017;17(1):294.
20. Hysong SJ, Best RG, Pugh JA. Audit and feedback and clinical practice guideline adherence: making feedback actionable. Implement Sci. 2006;1:9.

21. Ivers N, Jamtvedt G, Flottorp S, Young JM, Odgaard-Jensen J, French SD, et al. Audit and feedback: effects on professional practice and healthcare outcomes. Cochrane Database Syst Rev. 2012;6:CD000259.

22. Ivers NM, Sales A, Colquhoun H, Michie S, Foy R, Francis JJ, et al. No more 'business as usual' with audit and feedback interventions: towards an agenda for a reinvigorated intervention. Implement Sci. 2014;9:14.

23. Improved Clinical Effectiveness through Behavioural Research G. Designing theoretically-informed implementation interventions. Implement Sci. 2006;1:4.

24. Chamberlain P, Brown CH, Saldana L. Observational measure of implementation progress in community based settings: the Stages of Implementation Completion (SIC). Implement Sci. 2011;6:116.
Ready to submit your research? Choose BMC and benefit from:

- fast, convenient online submission

- thorough peer review by experienced researchers in your field

- rapid publication on acceptance

- support for research data, including large and complex data types

- gold Open Access which fosters wider collaboration and increased citations

- maximum visibility for your research: over $100 \mathrm{M}$ website views per year

At BMC, research is always in progress.

Learn more biomedcentral.com/submissions 